\title{
Prevalence of echinococcosis in humans, livestock and dogs in northern Italy
}

\author{
M. T. MANFREDI ${ }^{1}$, A. R. DI CERBO ${ }^{1}$, S. ZANZANI ${ }^{1}$, A. MORIGGIA ${ }^{2}$, D. FATTORI ${ }^{3}$, A. SIBONI ${ }^{3}$, V. \\ BONAZZA $^{4}$, C. FILICE ${ }^{2}$, E. BRUNETTI ${ }^{2}$
}

\begin{abstract}
${ }^{1}$ Dipartimento Patologia Animale, Igiene e Sanità Pubblica Veterinaria, Sez. Patologia Generale Veterinaria e Parassitologia, Università degli Studi di Milano, Milano, Italy, E-mail: mariateresa.manfredi@unimi.it $;{ }^{2}$ Divisione di Malattie Infettive e Tropicali, Università di Pavia, IRCCS Fondazione S.Matteo, Pavia, Italy; ${ }^{3}$ Asl provincia di Lodi c/o Inalca, Ospitaletto Lodigiano (LO), Italy; ${ }^{4}$ Osservatorio Epidemiologico Veterinario della Regione Lombardia I.Z.S.L.E.R. "B. Ubertini", Brescia, Italy
\end{abstract}

\begin{abstract}
Summary
The presence of Echinococcus sp. cysts was investigated in 822 sheep, 123 goats and 112,521 cattle from Lombardy region, North Italy. Faecal samples from 40 sheepdogs were also analyzed, with 9 samples containing taeniid eggs (22.5\%), 8 samples being coproantigen-positive $(20 \%)$, and one dog from a northern province (Lecco) positively confirmed by PCR. Cystic Echinococcosis (CE) was detected in $0.36 \%$ of sheep and in $0.29 \%$ of cattle in 2004 . No goat resulted to be infected. Data from CE patients treated in Lombardy were collected by inspecting hospital discharge records. In 2004, 156 CE-related admissions (62 $\%$ male and $38 \%$ female) were reported in Lombardy. Total hospital stay was 1,372 days $(1,286$ for inpatients, 86 for outpatients). Most patients (72.4\%) were residents in Lombardy and $1.9 \%$ were from Piedmont; the remaining patients were from central and southern Italy. According to acquired data $\mathrm{CE}$ resulted hypoendemic in animals in Lombardy. Prevalence rates in humans were higher than expected in this region, usually considered as non-endemic. Assessment of the prevalence of CE in humans remains a difficult, costly, time-consuming and labourintensive task. The present study suggests establishing a National Registry of Cystic Echinococcosis with the aim to highlight regional risk factors and to benefit from its matching both clinical and epidemiological data.
\end{abstract}

Keywords: Sheep, Goat, Human, Dog, Cattle, Echinococcus granulosus, Italy, prevalence, hydatid cysts

\section{Introduction}

Cystic Echinococcosis (CE) or hydatid disease, is caused by the tapeworm Echinococcus granulosus (Cestoda, Taenidae) and is one of the most widespread parasitic diseases in the Mediterranean region (Eckert et al., 2001; Dakkak,
2010). The disease is endemic in Italy, being most prevalent in the southern regions and the islands of Sardinia and Sicily (Garippa et al., 2004; Garippa \& Manfredi, 2009). Previous studies at abattoirs in northern Italy showed prevalence values below $1 \%$ in both sheep and cattle (Garippa et al., 2004; Garippa \& Manfredi, 2009). In humans, the mean annual CE incidence rates per 100,000 in the population (surgical cases) in southern Italy were $6.62-9.77,2.30$ and 2.33 in Sardinia, Sicily and Apulia, respectively; data from northern Italy reported a mean annual incidence rate of surgical cases equal to 1.57 per 100,000 inhabitants in Emilia Romagna and 9 CE cases in Veneto between 2000 and 2003 (Gabriele et al., 2004; Conchedda et al., 2010).

In an epidemiological study based on molecular approach, it was determined that the genotypes G1, G2 and G5 of the E. granulosus complex are circulating among cattle from North Italy even in Lombardy (Casulli et al., 2008).

Reliable data on prevalence in humans are actually few. The clinical presentation of the disease in humans is complex, as echinococcal cysts may remain clinically silent for years, and the compulsory notification of CE to the Italian Ministry of Health has been discontinued since 1991 (D. Min. San. 15.12.1991). Thus, prevalence of CE in humans may be underreported.

On the other hand, the European Directive 2003/99/CE and the subsequent Italian regulations (Italian D.L. 4 April 2006, n. 191) officially included CE among zoonoses under surveillance. As CE is strictly related to zootechnical production, the aim of this paper was to assess prevalence of CE in intermediate hosts (both animals and humans) in Lombardy, the most populated area in northern Italy, which has the largest share of land allocated to agricultural and zootechnical uses. Prevalence of infection due to Echinococcus was also assessed in definitive hosts. 


\section{Materials and methods}

Study area

Lombardy, located in northern Italy (Latitude: $45^{\circ} 40^{\prime} \mathrm{N}$; Longitude: $\left.9^{\circ} 30^{\prime} \mathrm{E}\right)$, consists of mountains (40.5\%), hilly areas $(12.5 \%)$, and the vast River Po plain $(47 \%)$. Of the entire $23,859 \mathrm{~km}^{2}$ surface, $46.7 \%$ is allocated to agriculture, $19.2 \%$ is covered by woodland, $13.2 \%$ is uncultivated or used as pasture areas, and $8 \%$ is occupied by buildings and infrastructures. Its rural territory is generally associated with agricultural and zootechnical activities, with over $1,650,948$ cattle $(37.8 \%$ of the total amount of cattle bred in northern Italy), 75,211 sheep and 46,366 goats bred in farms (Data ISTAT, December 2006).

Lombardy is the most densely populated Italian region with $9,545,441$ residents ( $16.1 \%$ of the Italian population; ISTAT, December 2007) at a density of 397 inhabitants / $\mathrm{km}^{2}$. Massive immigration from southern Italy occurred during the 1950s and 1960s, and in recent years (1980s and 1990s) foreign immigrants have entered the regional population. In the last five years, the number of foreign immigrants living in Lombardy has increased from 326,292 to 728,647. Foreign immigrants currently account for approximately $7.6 \%$ of the total regional population (of whom $34.1 \%$ are from other European countries, $22.1 \%$ from Africa, $22.1 \%$ from Asia, $0.1 \%$ from America and less than $0.1 \%$ from Oceania or are stateless) (Data from ISTAT, December 2006).

\section{Assessment of CE infection in animal hosts}

During 2004, a study investigating the presence of the cyst of Echinococcus sp. in intermediate hosts in 822 sheep (446 adults and 376 lambs) and 123 goats (94 adults and 29 kids) originating from Milan, Lecco, Varese, Como, Bergamo and Brescia provinces, was conducted. Cattle from the largest slaughterhouse in Italy (INALCA S.p.A., Lodi, Lombardy) were also included in the survey. A total of 215,559 animals originating from all Italian regions were slaughtered at the abattoir in 2004. The recorded data of infected cattle belonging to Lombard farms and data from the Cattle National Register were checked to select only cattle born or bred for more than two years in Lombardy. Cattle kept on Lombard farms for only several days or weeks were not included in this study. Thus, a total of 112,521 cattle from 5708 farms were selected. For each host species the presence of hydatid cysts was assessed at the abattoir.

Hydatid cysts were removed from the animals'organs and evaluated in a laboratory. They were counted and ranked as: fertile cysts, sterile cysts, cysts with purulent inflammation and/or caseous necrosis and calcified cysts. Cysts were dissected, and their germinal layer and protoscoleces were collected. The viability of protoscoleces was assessed by morphology, movement and presence of flame cells and, when necessary, by neutral red viable staining (Scala et al., 2006).

A geographical information system (GIS) was established utilizing the administrative boundaries (at provincial and

Table 1. Cystic Echinococcosis infection in cattle referred to Lombard provinces

\begin{tabular}{|c|c|c|c|c|c|}
\hline Province & $\begin{array}{c}\text { Total No. } \\
\text { of slaughtered } \\
\text { cattle }\end{array}$ & No. of cases & $\begin{array}{c}\text { Prevalence } \\
\text { per province } \\
\% \\
(95 \% \mathrm{CI}) \\
\end{array}$ & $\begin{array}{l}\text { No. of slaughtered cattle } \\
\text { in positive farms } \\
\text { (No. of positive farms) }\end{array}$ & $\begin{array}{c}\text { Frequency of infection } \\
\text { in positive farms } \\
\% \\
(95 \% \mathrm{CI})\end{array}$ \\
\hline $\mathrm{BG}$ & 13937 & 52 & $\begin{array}{c}0.37 \\
(0.28-0.49)\end{array}$ & $\begin{array}{l}1528 \\
(45)\end{array}$ & $\begin{array}{c}3.4 \\
(2.57-4.47)\end{array}$ \\
\hline $\mathrm{BS}$ & 32251 & 106 & $\begin{array}{c}0.33 \\
(0.27-0.40)\end{array}$ & $\begin{array}{l}3377 \\
(89)\end{array}$ & $\begin{array}{c}3.14 \\
(2.59-3.8)\end{array}$ \\
\hline CR & 27264 & 59 & $\begin{array}{c}0.22 \\
(0.17-0.29)\end{array}$ & $\begin{array}{l}2522 \\
(56)\end{array}$ & $\begin{array}{c}2.34 \\
(1.8-3.03)\end{array}$ \\
\hline $\mathrm{LO}$ & 13373 & 29 & $\begin{array}{c}0.22 \\
(0.15-0.32)\end{array}$ & $\begin{array}{l}1565 \\
(27)\end{array}$ & $\begin{array}{c}1.85 \\
(1.26-2.68)\end{array}$ \\
\hline MI & 9268 & 28 & $\begin{array}{c}0.30 \\
(0.20-0.44)\end{array}$ & $\begin{array}{l}1219 \\
(24)\end{array}$ & $\begin{array}{c}2.30 \\
(1.56-3.35)\end{array}$ \\
\hline $\mathrm{MN}$ & 11841 & 29 & $\begin{array}{c}0.24 \\
(0.16-0.35)\end{array}$ & $\begin{array}{l}649 \\
(29)\end{array}$ & $\begin{array}{c}4.47 \\
(3.07-6.43)\end{array}$ \\
\hline PV & 3070 & 15 & $\begin{array}{c}0.49 \\
(0.29-0.83)\end{array}$ & $\begin{array}{l}302 \\
(12)\end{array}$ & $\begin{array}{c}4.97 \\
(2.91-8.24)\end{array}$ \\
\hline $\mathrm{SO}$ & 483 & 1 & $\begin{array}{c}0.21 \\
(0.01-1.34)\end{array}$ & $\begin{array}{c}4 \\
(1)\end{array}$ & $\begin{array}{c}25.00 \\
(1.32-78.06)\end{array}$ \\
\hline VA & 796 & 2 & $\begin{array}{c}0.25 \\
(0.04-1.01)\end{array}$ & $\begin{array}{l}56 \\
(2)\end{array}$ & $\begin{array}{c}3.57 \\
(0.98-12.12)\end{array}$ \\
\hline TOT & 112521 & 321 & $\begin{array}{c}0.29 \\
(0.26-0.32) \\
\end{array}$ & $\begin{array}{l}11222 \\
(285)\end{array}$ & $\begin{array}{c}2.86 \\
(2.57-3.18) \\
\end{array}$ \\
\hline
\end{tabular}

BG - Bergamo, BS - Brescia, CR - Cremona, LO - Lodi, MI - Milano, MN - Mantova, PV - Pavia, SO - Sondrio, 
municipal level) of Lombardy region (Dati Geografici di Sintesi of Lombardy Region, vers. 1.2, 2003). All farms in the study area were geo-referenced and spatial distribution was investigated. Thematic layers of "land coverage" and "altitude" were used to assign topographic attributes to each farm.

To study the occurrence of CE infection in definitive hosts, faecal samples from 40 sheepdogs living in Lombard farms were collected and analyzed using a CA-ELISA commercial kit (CHEKIT-Echinotest, Bommeli Diagnostic, Liebefeld-Bern, Switzerland) and/or by the flotation technique. The diagnosis of canine echinococcosis in positive animals was confirmed through nested PCR that was carried out by an external laboratory (Department of Infectious, Parasitic and Immunomediated Disease, Istituto Superiore di Sanità, Rome, Italy).

Sensitivity and specificity of CA-ELISA test, positive predictive value (PPV), negative predictive value (NPV), true and apparent prevalences of Echinococcus in dogs were calculated using the Win Episcope 2.0 software (EPIDECON, BorlandDelphiC) (Thrusfield et al., 2001). Youden's index $(\mathrm{J})$ was applied to evaluate the reliability of the diagnostic test (Armitage \& Berry, 1987).

\section{Assessment of CE infection in humans}

Data from CE human cases in Lombardy were collected by inspecting hospital discharge records (HDR) obtained in 2004 from the Lombardy Department of Health Services (Assessorato Regionale alla Sanità). Discharges with any diagnostic code related to $\mathrm{CE}$ were entered in the database, including inpatients and patients seen on a Day-Hospital basis. Diagnoses and surgical interventions were codified according to the International Classification of Disease IX Clinical Modification (ICD-IX-CM; WHO 1997).

All data were statistically processed by SPSS version 16.0 software (SPSS Inc., Chicago, IL, USA).

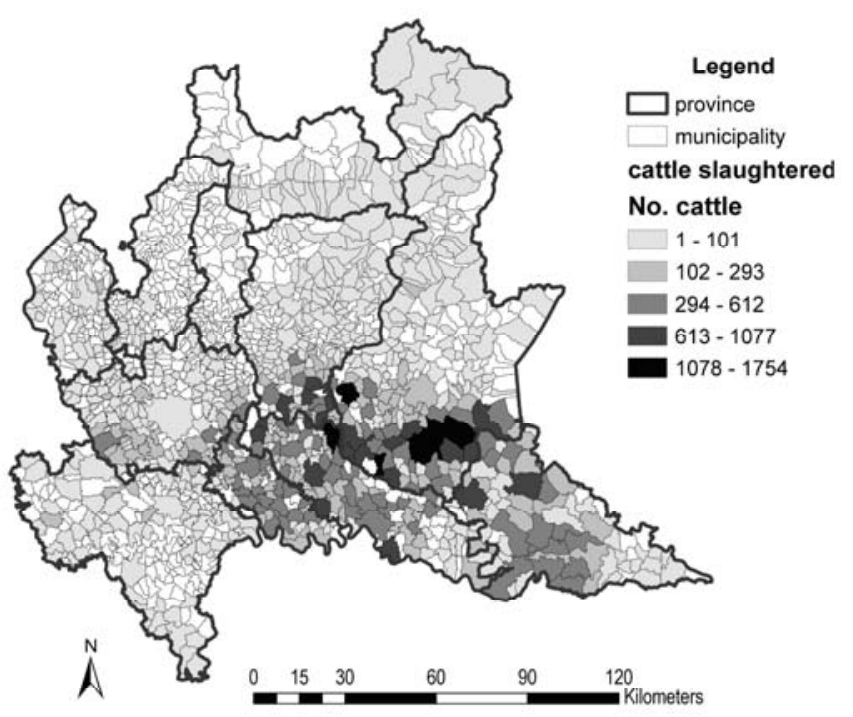

\section{Results}

\section{CE infection in animal hosts}

Infection with Echinococcus sp. in intermediate hosts was detected in 3 out of 822 sheep $(\mathrm{P}=0.36 \%$; $95 \%$ confidence interval [CI]: $0.12 \%-1.06 \%$ ) and 321 out of 112,521 dairy cattle included in this study $(\mathrm{P}=0.29 \%$; $95 \% \mathrm{CI}$ : $0.26 \%-0.32 \%$ ) (Table 1$)$. None of the examined goats showed hydatid cysts.

Infected sheep originated from an abattoir in Lecco province. Among adults (446 animals), the percentage of CEpositive sheep was $0.67 \%$ (95\% CI: $0.23 \%-1.95 \%$ ), while none of the 376 lambs were infected with CE. Sheep examined at the abattoirs were also positive for other zoonotic parasites, such as the trematodes of genera Dicrocoelium and Fasciola, and the larval cestode Cysticercus tenuicollis $(\mathrm{P}=10.9 \%, \mathrm{P}=0.36 \%$ and $\mathrm{P}=0.61 \%$, respectively).

Cattle with hydatid cysts were almost all females (96.9\%) and ranged from 1 to 17 years old (median $\pm \mathrm{SD}=6.0 \pm$ 3.1 years old). The main races were Holstein and Brown Swiss ( $77 \%$ and $8 \%$, respectively); the remaining animals belonged to other minor races or were half-breed. Infected cattle originated from 285 of 5708 farms (4.99\%) in the survey; these farms were distributed among 195 of the 812 municipalities included in this study $(24.01 \%)$.

On farms with animals positive for CE, the rate of infected animals was $2.86 \%$ (95\% CI: $2.57 \%-3.18 \%$; a total number of 11,222 slaughtered cattle). The number of infected cattle ranged from 1 to 5 animals per farm; specifically, $90.5 \%$ of the farms had 1 infected head, $7 \%$ had 2 heads, $1.75 \%$ had 3 heads, and $0.35 \%$ had 4 or 5 heads. A cartographic representation of the location of these farms was performed in the GIS system and a choropleth map depicting infection spread was created at municipality level (Fig. 1).

Fig. 1. Choropleth map on the total number of cattle slaughtered (left) and positive animals for CE (right) in each municipality

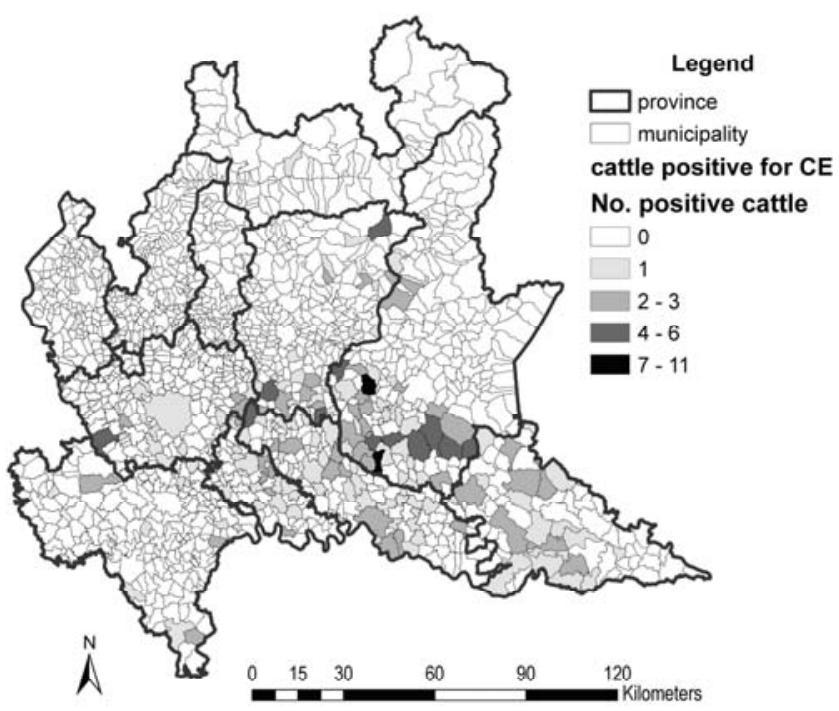




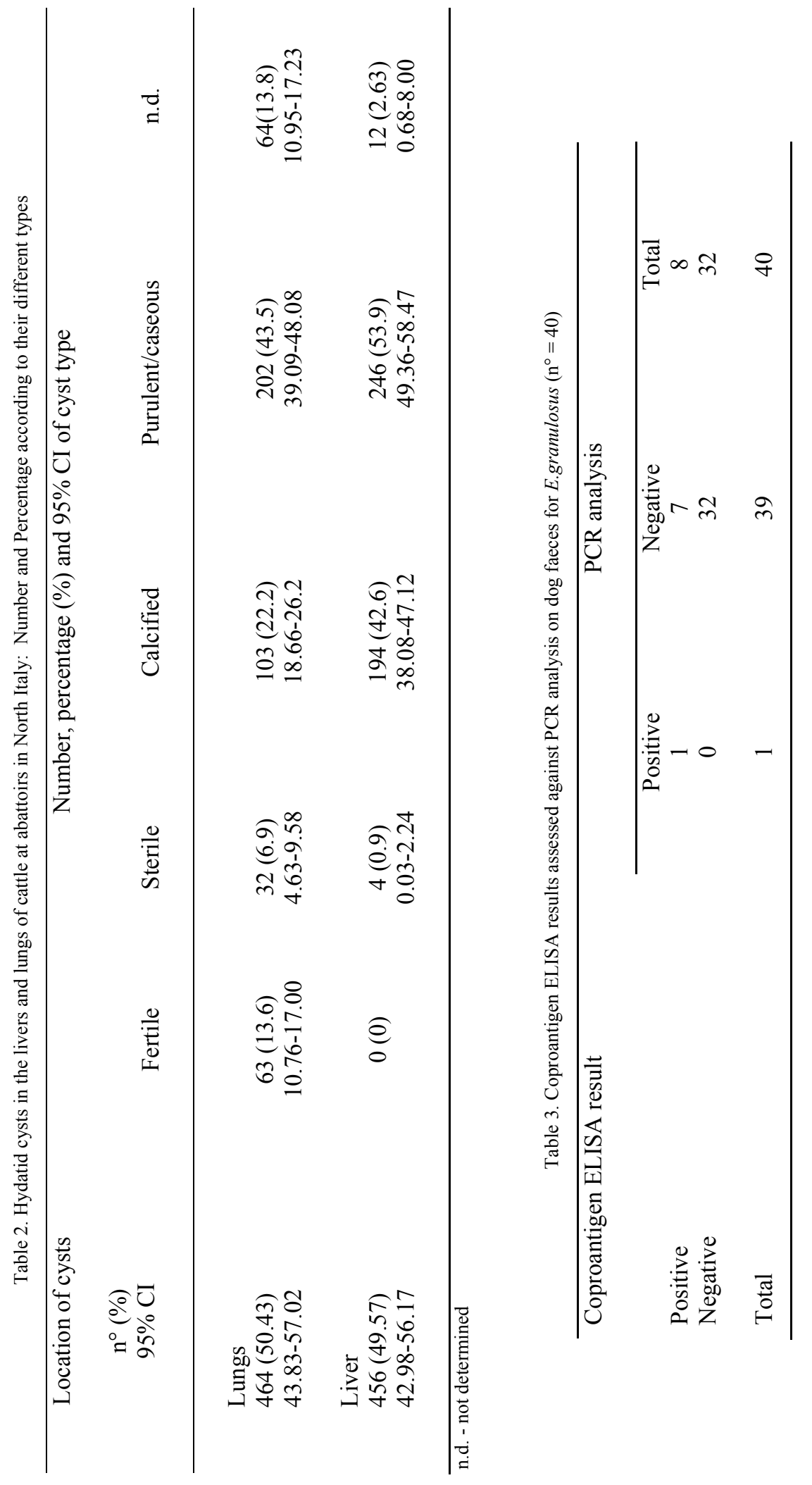


Table 4. Diagnostic data on coprological prevalence of Echinococcus granulosus in sheepdogs by CA-ELISA

\begin{tabular}{lccc}
\hline & value & Lower limit (95\% CI) & Upper limit (95\% CI) \\
\hline Sensitivity (\%) & 100 & 100 & 100 \\
Specificity (\%) & 82.051 & 70.007 & 94.096 \\
True prevalence (\%) & 2.5 & 0 & 7.338 \\
Apparent prevalence (\%) & 20 & 7.604 & 32.396 \\
Positive predictive value (\%) & 12.5 & 0 & 35.418 \\
Negative predictive value (\%) & 100 & 100 & 100 \\
Youden's J & 0.8205 & 0.7001 & 0.9410 \\
\hline
\end{tabular}

Comparing the observed prevalence with altitude and land use data, $95.4 \%$ of farms with CE-positive animals were located at altitudes below $500 \mathrm{~m}$ a.s.1. (min-max: $100-$ $1300 \mathrm{~m}$ a.s.1.; median \pm SD: $100.0 \pm 172.4 \mathrm{~m}$ a.s.1.). Most farms were located in traditionally agricultural areas $(78.9 \%)$, while a rather significant percentage was related with urban or suburban areas (14.7\%) or other land categories, such as meadow or pasture land $(3.8 \%)$ and deciduous forest $(1.8 \%)$.

The frequency of the different cyst categories found in cattle are shown in Table 2. A total of nine hundred and twenty hydatid cysts were collected, four hundred and sixty four $(50.43 \%)$ were from lungs and four hundred and fifty six $(49.57 \%)$ were from liver. The frequency of fertile cysts was lower than other categories (calcified and purulent/caseous type) and they were only found in lungs (13.6\%).

With regard to definitive hosts, coprological analyses indicated that 9 of the 40 sheepdog faeces samples harboured taeniid eggs $(22.5 \%)$, and one dog was infected with Sarcocystis sp. Enzyme-linked immunosorbent assay (CAELISA) confirmed 8 Echinococcus coproantigen-positive faecal samples from dogs $(20 \%), 2$ of which contained taeniids eggs as determined by coprological examinations (Table 3). PCR analysis performed on dog faeces confirmed only one case of E. granulosus infection in a dog from the province of Lecco.

We used PCR results as the gold standard for assessing the sensitivity and specificity of CA-ELISA. Diagnostic data on the coprological prevalence of E. granulosus in sheepdogs are shown in Table 4. Apparent prevalence was $20 \%$, whereas true prevalence decreased to $2.5 \%$.

\section{CE infection in humans}

Data were provided from the Lombardy Department of Health Services as an anonymized spreadsheet with attendant DRG (Diagnosis-Related Group) codes. No data regarding occupation of the patients were available. Most importantly, as clinical records were not accessible, no information was available about cyst stages (active, transitional, or inactive) or the type of procedure used.

In 2004, 156 CE-related admissions were recorded (110 inpatients, and 46 outpatients seen on a day-hospital basis) in Lombardy. Ninety-seven patients (62\%) were male, and $59(38 \%)$ were female. Hepatic involvement was diagnosed in 124 patients (79\%), 25 of whom (20\%) underwent surgery. Cysts were also found in lungs (13.5\%) and other organs $(7 \%)$. Total hospital stay was 1,372 days (1,286 for inpatients, and 86 for day-hospital patients). The mean hospital stay was 11 days for inpatients and 2 days for day-hospital patients. Total costs for the regional health system were $€ 483.608,00$, with $€ 471.173$ for inpatients and $€ 12.435$ for patients seen on a day-hospital basis.

The prevalence of CE (number of cases per 100,000 inhabitants) was highest in the oldest age class (Table 5).

Most patients $(73.3 \%)$ were residents in northern regions: $72.4 \%$ lived in Lombardy and $1.9 \%$ were from Piedmont; the remaining patients were from central and southern Italy (Latium $1.2 \%$, Tuscany $0.6 \%$, Apulia $2.5 \%$, Calabria $5.1 \%$, Sicily $2.5 \%$, Sardinia $6.4 \%$ ) or from other countries $(7 \%)$. The prevalence of $\mathrm{CE}$ among residents of Lombardy was higher in Brescia and Cremona than in other provinces (Table 6).

Table 5. Human cystic echinococcosis (CE) and its crude rate by age according to demographical data related to Lombard resident population (ISTAT, 2004)

\begin{tabular}{cccc}
\hline $\begin{array}{c}\text { Age } \\
\text { (years) }\end{array}$ & $\begin{array}{c}\text { Number } \\
\text { of CE cases registered in 2004 }\end{array}$ & $\begin{array}{c}\text { Lombard resident population in } \\
2004\end{array}$ & $\begin{array}{c}\text { CE annual crude rate } \\
\text { (per 100,000 inhabitants) }\end{array}$ \\
\hline $0-9$ & 0 & 836422 & 0 \\
$0-19$ & 7 & 803164 & 0.87 \\
$20-29$ & 27 & 1103747 & 2.45 \\
$30-39$ & 35 & 1600166 & 2.19 \\
$40-49$ & 25 & 1361664 & 1.83 \\
$50-59$ & 18 & 1221539 & 1.47 \\
$60-69$ & 23 & 1108957 & 2.07 \\
$70-79$ & 8 & 802858 & 1.0 \\
$>80$ & 13 & 408279 & 3.18 \\
\hline
\end{tabular}


Table 6. Prevalence of human cystic echinococcosis (CE) by province of origin according to demographical data related to Lombard resident population (ISTAT, 2004)

\begin{tabular}{cccc}
\hline Province & $\begin{array}{c}\text { Number } \\
\text { of CEses registered } \\
\text { in 2004 }\end{array}$ & $\begin{array}{c}\text { Lombard resident } \\
\text { population in 2004 }\end{array}$ & $\begin{array}{c}\text { CE annual crude rate } \\
\text { (per 100,000 inhabitants) }\end{array}$ \\
\hline BG & 2 & 495144 & 0.40 \\
BS & 16 & 565908 & 2.83 \\
CO & 13 & 537500 & 2.42 \\
CR & 9 & 335939 & 2.68 \\
LC & 4 & 311452 & 1.28 \\
LO & 2 & 197672 & 1.01 \\
MI & 47 & 3707210 & 1.27 \\
MN & 6 & 377790 & 1.59 \\
PV & 3 & 493753 & 0.61 \\
SO & 0 & 176856 & 0 \\
VA & 11 & 812477 & 1.35 \\
TOT & 113 & 9246796 & 1.22 \\
\hline
\end{tabular}

BG- Bergamo, BS- Brescia, CO- Como, CR- Cremona, LC- Lecco, LO- Lodi, MI- Milano, MN- Mantova, PV- Pavia, SO- Sondrio, VA- Varese

\section{Discussion}

Our data confirm that animal CE is hypoendemic in Lombardy. In cattle, the prevalence of CE seems to be sporadic, with $1-5$ animals positive for $\mathrm{CE}$ per farm. Our findings agree with those previously collected at the same abattoir (INALCA S.p.A.) and reported by Fattori et al. (2000). Their study showed a prevalence of $0.2 \%$ in slaughtered cattle originating from farms of northern Italy (we herein report prevalence of $0.29 \%$ in Lombardy). In the present study CE prevalence in sheep from Lombardy $(0.36 \%)$ was lower than the one found in other areas of northern Italy according to the above named study (Garippa et al., 2004). Data collected in sheep (a total of 1418 sheep) from Piedmont revealed a $0.63 \%$ prevalence of CE $(95 \% \mathrm{CI}$ : $0.31-1.24 \%)$, whereas none of the examined goats (208 goats) were positive for CE (Manfredi \& Di Cerbo, unpublished data).

However, while data on $\mathrm{CE}$ in cattle fairly correctly indicate the prevalence of $\mathrm{CE}$ because they were collected from animals of all ages, the lower prevalence seen in small ruminants might be due to the fact that old sheep and goats are rarely slaughtered under veterinary control. Thus, the real CE prevalence might be underestimated given that only data from young animals are reported.

As to cattle, most animals were housed indoor and could enter an outdoor paddock. They originated from farms surrounded by wide fields, where green fodder is produced and still supplemented to the diet of dairy cattle. The origin of cattle infection could reasonably be due to contamination of these fields by sheepdogs that follow transhumant flocks. Transhumance is still practiced in Lombardy and sheep are moved seasonally, from alpine pastures to lowlands in winter and vice versa in summer.

Displacement analysis of several transhumant flocks of 400 to 2000 sheep, each moving seasonally in Lombardy, indicate that they follow the main routes (north to south) passing through Bergamo and Brescia provinces down to the River Po plain areas (Manfredi \& Di Cerbo, unpublished data). Here, farms showing infected cattle seem to be located along the routes followed by transhumant sheep herds. Sheepdogs or farm dogs could become infected with Echinococcus by ingestion of offal from sheep found dead near the farms or discharged after home slaughtering of sheep; subsequently, their faeces might contaminate the fields, causing the enclosed cattle to become infected via ingestion of green fodder contaminated with taeniid eggs.

However, the low prevalence $(2.5 \%)$ of infected dogs coupled with the low quantity of green fodder in the diet of the enclosed cattle explained the low prevalence of $\mathrm{CE}$ also shown in cattle. Otherwise, it is important to note that a lot of municipalities were involved in the parasite cycle, and that they were mostly located in the River Po plain (see map). Thus, infected cattle might be a little higher in number than what resulted in the study; in fact, cattle from alpine areas are usually slaughtered in small local abattoirs, which made it impossible to us to register more cases of $\mathrm{CE}$ in cattle from there. Furthermore, the presence of Echinococcus in those areas is evidence of human health risk, though not yet considered for such places as they are not pertaining to traditionally harmful sites as the ones associated to sheep breeding. Another observation emerging from the analysis of epidemiological data on farm animals is that data collected at the abattoir, mainly that regarding sheep and goats, cannot depict correctly the epidemiological scenario in a region like Lombardy with a low endemicity for CE. Collected data confirm that epidemiological surveys are needed to monitor this important zoonosis and a different approach could be required (as serology) to detect CE in intermediate hosts.

This is what is strongly suggested by data reported in the last EFSA report (2010) still minimizing the impact of the most important zoonoses known given the fact that no human cases of CE is reported from 2004 to 2008 in Italy; 
nonetheless, actual data should enhance concern on the issue, as Conchedda et al.,(2010) demonstrated indicating an incidence rate of clinical cases similar to 14.0 per 100,000 inhabitants from pastoral areas.

\section{CE in humans}

Clinical presentation of $\mathrm{CE}$ in humans is complex and polarized, as it may remain clinically silent for years, but may also feature life-threatening complications (e.g., anaphylactic shock, paralysis, embolism) depending on the cyst stage and location. CE in humans is usually diagnosed incidentally during the work-up for other clinical problems or due to complications; hence, its true incidence is difficult to determine.

In Italy, compulsory notification of CE to the Italian Ministry of Health was discontinued in 1991, and consistently with the current legislation, the Ministry of Health requires only a summary of the regional cases. Therefore, data of $\mathrm{CE}$ are no longer submitted to the Central Institute of Statistics (ISTAT), thus making the assessment of human CE prevalence more burdensome. To circumvent this problem, and following the pioneering work by research group of Ostanello in Emilia Romagna (Ostanello et al., 1997), we analyzed Hospital Discharge Records (HDR) to study the prevalence of the disease in our region.

Analysis of HDR has several advantages; in fact, a quick access to their database (where available, as some regions do not store data via electronic files) allows the collection of information, such as: number of hospitalization days, expenses charged to National Health Service (NHS), number of residents hospitalized in other Italian regions, and non-surgical cases. It is, however, impossible to determine the occupation of patients, which could help to establish assessments for infection risk and procedures leading to diagnosis, and to obtain information about cyst stages (active, transitional or inactive) (World Health Organization Informal Working Group, 2003), or the type of procedures used. Moreover, data of outpatients are missing because these patients are not admitted or discharged, which greatly impairs the quality of results.

Despite these challenges, the figures of human CE prevalence were higher than expected, given the low CE prevalence in animals and the fact that Lombardy has traditionally been considered a low prevalence area.

Specifically, our figures (156 CE-related admissions) are higher than those obtained in Tuscany (Montinaro et al., 2004), Emilia Romagna (Battelli et al., 2004), and Apulia (Punzo et al.,, 2002), who reported 695 cases in 1997 2002, 511 in 1995 - 2001, and 468 in $1996-2000$, respectively. This indicates a mean per year of 116 cases in Tuscany, 73 cases in Emilia Romagna, and 93 cases in Apulia. It is not clear, however, whether patients with $\mathrm{CE}$ in Lombardy were born there or in other endemic regions, where they first became infected before migrating to Lombardy. Data on patients' region of birth were not available. We speculate that these limitations could be overcome, at a relatively low cost, with the establishment of a National
Registry for $\mathrm{CE}$ based on Internet electronic data entry, following the example set by the European Registry for Alveolar Echinococcosis (Kern et al., 2003).

The registry would streamline and further the study of CE by eliminating the need for evaluating and integrating separate data from multiple regions, by avoiding duplication of data from patients who access several different health facilities over time, and by providing much needed clinical and epidemiological data that are fully accessible to single clinicians. The registry would also include data from outpatients, and avoid conflicting data from the hospitalization of subjects seen regularly as outpatients.

Data collected in intermediate and definitive hosts demonstrated the presence of an autochthonous cycle of $E$. granulosus in Lombardy. The presence of hydatid cysts in cattle from an intensively managed cattle area indicates a possible zoonotic risk for humans. However, cattle are unlikely to contribute to E. granulosus spread, as cattle are regularly slaughtered and their offal appropriately discharged. Furthermore, G1 was the dominant strain in the region and cysts with $\mathrm{G} 1$ (common sheep strain) are unfertile or exhibit low fertility in cattle (Varcasia et al., 2006). Thus, we assume that the spread of E. granulosus is predominantly linked to the sheep-dog cycle in Lombardy as it is in the Italian regions endemic for CE. The low prevalence of $\mathrm{CE}$ found in sheep and goat might be a consequence of the young age of slaughtered ruminants and the home slaughtering of sheep, as it is known to be practiced. The cattle-adapted Echinococcus ortleppi, which causes mostly fertile pulmonary cysts and is characterized by the rapid growth of adult worms in dogs (Thompson \& McManus, 2002), has been recently found in cattle bred in Lombardy (Casulli et al., 2008). Whether this constitutes a potential risk for humans in Lombardy (anecdotal reports exist of cysts caused by E. ortleppi in humans) remains to be seen and warrants further research.

Prevalence rates in humans turned out to be higher than expected for a region deemed non-endemic, although it was impossible to determine whether $\mathrm{CE}$ infection had occurred locally or was transmitted from other regions with higher endemicity. Nevertheless, costs sustained by Lombardy Regional Health System were remarkable. Although incomplete, these data provide a more realistic picture of the prevalence of CE in northern Italy, especially if we compare our data with the official reports published, for instance, by the European Food Safety Authority, EFSA, which reported no human cases in Italy during 2004 (European Food Safety Authority, 2005, 2010).

Our studies strongly suggest that assessment of the prevalence of human CE remains a difficult, costly, time-consuming and labour-intensive task. Our proposal for the National Registry of Cystic Echinococcosis could offer a solution to a number of problems hampering data collection in this field. CE warrants more attention from clinicians, and coordination with veterinarians and policy-makers is required to implement a more effective approach for CE control. 


\section{Acknowledgements}

This study was supported by PRIN 2003 Prot. 2003070410 (to MTM) and partly by INCO-MED 509102 (to EB).

$\mathrm{EB}, \mathrm{AM}$ and $\mathrm{CF}$ gratefully acknowledge the collaboration of Assessorato alla Sanità della Regione Lombardia for providing them with the data on CE patients discharged from Hospitals in Lombardy during 2004.

\section{References}

Armitage, P., Berry, G. (1987): Statistical methods in medical research. 2nd Edition. Blackwell Scientific Publications, $620 \mathrm{pp}$.

BAtTelli, G., OStanello, F., BALdelli, R., Di Francesco, A., GRILLI, R., VizIOLI, M. (2004): Human echinococcosis in the Emilia-Romagna region (northern Italy) in the years 1997 to 2002: an updating. Parassitologia, 46: 415 - 416

Brunetti, E., Garlaschelli, Al., Filice, C., Schantz, P. (2003): Comment on "Acute echinococcosis: a case report”. J. Clin. Microbiol., 41: 523. DOI: 10.1128/jcm.41. 1.523 .2003

Budke, C. M., Deplazes, P., Torgerson, P. R. (2006): Global socioeconomic impact of cystic echinococcosis. Emerg. Infect. Dis., 12: 296 - 303

Casulli, A., Manfredi, M. T., La Rosa, G., Di Cerbo, A. R., Genchi, C., PozIO, E. (2008): Echinococcus ortleppi and E. granulosus G1, G2 and G3 genotypes in Italian bovines. Vet. Parasitol., 155: 168 - 172. DOI: 10.1016/ j.physletb.2003.10.071

Conchedda, M., Antonelli, A., CAdDori, A., GABriele, F. (2010). A retrospective analysis of human cystic echinococcosis in Sardinia (Italy), an endemic Mediterranean region, from 2001 to 2005. Parasitol. Int., 59 (3), 454 459. DOI: $10.1016 /$ j.parint.2010.06.008

DAKKAK, A. (2010): Echinococcosis/hydatidosis: A severe threat in Mediterranean countries. Vet. Parasit., 174: 2 11. DOI: $10.1016 /$ j.vetpar.2010.08.009

ECKert, J., GemMell, M. A., Meslin, F. X., PAWlowski, Z. $\mathrm{S}$. (eds) 2001. WHO/OIE manual on echinococcosis in humans and animals: a public health problem of global concern. World Health Organisation for Animal Health, Paris. EUROPEAN FoOd SAFETY AUTHORITY (2005): The Community Summary Report on Trends and sources of zoonoses, zoonotic agents and antimicrobial resistance in the European Union in 2004. The EFSA Journal, 310 pp. DOI: $10.2903 /$ j.efsa.2010.1496

EUROPEAN FOOD SAFETY AUTHORITY (2010): Trends and sources of zoonoses and zoonotic agents and food-borne outbreaks in the European Union in 2008. The EFSA Journal, 2010 8(1), 1496, 370 pp. DOI: 10.2903/j.efsa.2009. 1438

FAtTori, D., Biggioggero, S., Dordoni, E., Morici, R., Perri, M., Prandi, N., Tessuto, L. (2000): Epidemiology in the biggest european slaughterhouse. L'Osservatorio, 2: $8-9$

RECEIVED JUNE 3, 2010
Gabriele, F., Bortoletti, G., Conchedda, M., Palmas, C., ECCA, A. R. (2004): Human cystic echinococcosis in Italy: a public health problem? Past and present. Parassitologia , 46, $39-43$

GaripPa, G., BAtTelli, G., Cringoli, G., Giangaspero, A., GianNETto, S., MANFREDI, M. T. (2004): Updating on animal echinococcosis in Italy. Parassitologia, 46: $37-38$ Garippa, G., Manfredi, M. T. (2009). Cystic echinococcosis in Europe and in Italy. Vet Res Commun, 33 (suppl. 1): S35 - S39. DOI: 10.1007/s1 1259-009-9245-0

de Blas, N., Ortega, C., Frankena, K., Noordhuizen, K., ThruSFIELD, M.: Win Episcope 2, http://www.clive.ed. ac.uk/winepiscope/. Accessed May 2008.

ISTITUTO NAZIONALE DI STATISTICA (ISTAT): http://www. istat.it/. Accessed May 2008.

Kern, P., Bardonnet, K., Renner, E., Auer, H., Pawlowski, Z., Ammann, R. W., Vuitton, D. A., Kern, P. (2003): European echinococcosis registry: human alveolar echinococcosis, Europe, 1982 - 2000. Emerg. Infec. Dis., 9: 343 - 349.

Menezes DA Silva, A. (2003): Hydatid cyst of the livercriteria for the selection of appropriate treatment. Acta Trop., 85: 237 - 242. DOI: 10.1016/s0001-706x(02)00271-1 Montinaro, L., Sisinni, A. G., SARTorelli, P. (2004): Echinococcosis: a persistent endemic. G. Ital. Med. Lav. Ergon., 26: 202 - 207

Ostanello, F., Piccolomini. L. L., Martinello, F., Vizioli, M., BATTELLI, G. (1997): Echinococcosis/hydatidosis in Emilia-Romagna: a study of hospital admissions in the period of 1989 - 1993. Epidemiol. Prev., 21: $41-47$

Punzo, C., Mastrogiacomo, M., Germinario, C., De LEO, G., BonOMO, G. M. (2002): Hepatic hydatidosis in Puglia: analysis of the hospital discharge cards in the years 1996 - 2000. Ann. Ital. Chir., 73: $605-610$

ScAla, A., GaripPa, G., VArcasia, A., Tranquillo, V. M., GENCHI,C. (2006): Cystic echinococcosis in slaughtered sheep in Sardinia (Italy). Vet. Parasitol., 135: 33-38. DOI: 10.1016/j.vetpar.2006.01.016

ThOMPSON, R. C., MCMANUS, D. P. (2002): Towards a taxonomic revision of the genus Echinococcus. Trends Parasitol., 18: 452 - 457. DOI: 10.1016/s1471-4922(02)02358-9 Thrusfield, M., Ortega, C., De Blas, I., NoOrdhuizen, J. P., Frankena, K. (2001): WIN EPISCOPE 2.0: improved epidemiological software for veterinary medicine. Vet. Rec., 148: $567-572$

Varcasia, A., Canu, S., Lightowlers, M. W., Scala, A., GARIPPA, G. (2006): Molecular characterization of Echinococcus granulosus strains in Sardinia. Parasitol. Res., 98: 273-277. DOI : 10.1007/s00436-005-0059-x

WORLD HEALTH ORGANIZATION INFORMAL WORKING GROUP (2003): International classification of ultrasound images in cystic echinococcosis for application in clinical and field epidemiological settings. Acta Trop., 85: $253-$ 261. DOI: 10.1016/s0001-706x(02)00223-1 